\title{
Novel palladium nanoparticles supported on $\beta$ - cyclodextrin@graphene oxide as magnetically recyclable catalyst for Suzuki-Miyaura cross-coupling reaction with two different approaches in bio-based solvents
}

\author{
Bahareh Heidari $^{1}$, Majid M. Heravi ${ }^{1}$, Mohammad Reza Nabid ${ }^{2}$, Roya Sedghi ${ }^{2}$, Seyyed \\ $\operatorname{Emad}^{3}$
}

1- Department of Chemistry, Alzahra University, Vanak, Tehran, Iran

2- Department of Polymer and Materials Chemistry, Faculty of Chemistry and Petroleum Sciences, Shahid Beheshti University, GC, Tehran, 1983969411, Iran

3- Department of Organic Chemistry and Oil, Faculty of Chemistry and Petroleum Sciences, Shahid Beheshti University, GC, Tehran, 1983969411, Iran

\begin{abstract}
A novel nanocatalyst was designed and prepared. Initially, the surface of magnetic graphene oxide (M-GO) was modified using thionyl chloride, tris(hydroxymethyl)aminomethane and acryloyl chloride as linkers which provide reactive $\mathrm{C}=\mathrm{C}$ bonds for the polymerization of vinylic monomers. Separately, $\beta$-cyclodextrin ( $\beta$-CD) was treated with acryloyl chloride to provide a modified $\beta-\mathrm{CD}$. Then, in the presence methylenebisacrylamide as a crosslinker, monomers of modified $\beta-\mathrm{CD}$ and acrylamide were polymerized on the surface of the pre-prepared M-GO. Finally, palladium acetate and sodium borohydride were added to this composite to afford supported palladium nanoparticles. This fabricated nanocomposite was fully characterized using
\end{abstract}


Source: Heidari B, Heravi MM, Nabid MR, Sedghi R, Hooshmand SE. Novel palladium nanoparticles supported on $\beta$-cyclodextrin@ graphene oxide as magnetically recyclable catalyst for Suzuki-Miyaura crosscoupling reaction with two different approaches in bio-based solvents. Appl Organomet Chem. 2019;33(1). https://doi.org/10.1002/aoc.4632

various techniques. The efficiency of this easily separable and reusable heterogeneous catalyst was successfully examined in Suzuki-Miyaura crosscoupling reactions of aryl halides and boronic acid as well as in modified Suzuki-Miyaura cross-coupling reactions of $\mathrm{N}$-acylsuccinimides and boronic acid in green media. The results showed that the nanocatalyst was efficient in coupling reactions for direct formation of the corresponding biphenyl as well as benzophenone derivatives in green media based on bio-based solvents. In addition, the nanocatalyst was easily separable, using an external magnet, and could be reused several times without significant loss of activity under the optimum reaction conditions.

Keywords: bio-based solvents, host-guest interaction, magnetic graphene oxide (M-GO), palladium nanoparticles, Suzuki-Miyaura cross-coupling reaction 